\title{
Evaluation of Slope Assessment System in Predicting Landslides along Roads Underlain by Granitic Formation
}

\author{
${ }^{1}$ Bujang B.K. Huat and ${ }^{2}$ Jamaludin S. \\ ${ }^{1}$ Faculty of Engineering, University Putra Malaysia, Malaysia \\ ${ }^{2}$ Public Works Department, Malaysia
}

\begin{abstract}
A slope assessment is to estimate the probability of occurrence and likely severity of landslides in a given area. This study evaluates two existing Slope Assessment Systems (SAS) for predicting landslide at the micro level of assessment developed by the Public Works Department of Malaysia, namely the Slope Information Management System (SIMS) and the Slope Management and Risk Tracking System (SMART). From the results of this study, it appears that none of the existing SAS is satisfactory for predicting landslide in granitic formation, for various reasons such as the use of hazard score developed from another country and use of data-base derived from different rock formation. A new SAS was developed using nine-parameters equation that was based on the stepwise discriminant analysis. The new SAS appears to show a good capability in predicting landslides in granitic formations.
\end{abstract}

Keywords: Landslide, Granitic Formation, Slope Assessment System, Stepwise Discriminant Analysis

\section{INTRODUCTION}

Landslide is defined as the movement of a mass of rock, debris or earth down a slope [1]. The word landslide also refers to the geomorphic features that result from the event. Other terms used to refer to landslide include slope failures, slope instability and terrain instability [2]. Landslide may occur almost anywhere, from man-made slopes to natural, pristine ground. Most slides often occur in areas that have experienced sliding in the past. All landslides are triggered by similar causes.

Landslides have caused large numbers of casualties and huge economic losses in hilly and mountainous areas of the world. In tropical countries where annual rainfall can reach as high as $4500 \mathrm{~mm}$ and high temperatures around the year caused intense weathering to their soil and rock profile where in certain location can reach 100 $\mathrm{m}$ in depth [3]. With these set of climate and geological condition, combined with other causative factors, landslide is one of the most destructive natural disasters in tropical region. Malaysia is one of the countries located in the tropical region. From 1993 to 2004, there were 13 major landslides reported in Malaysia, involving both cut and natural slopes with a total lost of more than 100 lives.

Social and economic losses due to landslides can be reduced by means of effective planning and management which involved landslide hazard assessment, slope assessment for landslide prediction, mitigation measures and warning systems $[4,5]$.
Slope Assessment System (SAS) for estimation of the probability of occurrence and likely severity of landslides in a given area can be carried out by various approaches. According to Varnes [6], Soeters and Van Westen [7] there are four methods of slope hazard assessment, namely landslide inventory, heuristic approach, statistical approach and deterministic approach. Hussein et al. [8] described another assessment method called the overall score evaluation method. Irigaray and Chacón [9] discussed six methods of assessment namely percentage of rupture zones, intervals of critical slope angle, matrix, indexing, value of information and multiple regression. Ali [10], Rosenbaum et al. [11] and Tangestani [12] described an attempt to use of fuzzy set theory analysis for evaluating landslide hazard. Fractal dimension, a mathematical theory that describes the quality of complex shapes of images in the nature is claimed to be suitable for measuring landslides complex topography as reported by Kubota [13] and Yi et al. [14]. Results of these SAS can be presented in form of landslide hazard map, useful in development planning and in slope maintenance and management. It also can be combine with landslide consequences analysis to produced landslide risk map which can be used in prioritizing of maintenance works and in emergency and rescue preparedness.

In Malaysia, there are several government departments with different disciplines involved to reduce landslide hazard and their consequences, namely the Department 
of Mineral and Geosciences (DMG), Center of Remote Sensing (MACRES) and the Public Works Department (PWD). The SAS developed by MACRES and DMG are meant for macro level of assessment whereas the SAS developed by the PWD are meant for micro level of assessment.

To date, reliability or accuracy of the existing SAS in predicting the landslide occurrences in Malaysia are never really tested and are therefore questionable. Accuracy or reliability in predicting future landslide is a crucial part of any SAS. Missed prediction will exposed lives and economy to danger or hazard if a slope or an area that should has a High Hazard Level is missed predicted as Low Hazard Level. On other hand, if a slope or an area that should has a Low Hazard Level is missed predicted as High Hazard Level, it will be exposed to loss in term of money spending to 'stabilized' the stable slope, or money spending on any effort to lower down the risk of landslide that actually will not occur.

This study presents an attempt to evaluate the reliability and accuracy of two existing SAS in predicting landslide at the micro level of assessment. They are the Slope Information Management System (SIMS) and the Slope Management and Risk Tracking System (SMART).

Slope Assessment Systems and Field Sites: In evaluating the reliability and accuracy of the existing slope assessment systems in predicting landslides, field data were collected from existing cut and natural slopes. The number of recent landslides or failed slope is then compared with the number of slopes classified as high and very high hazard that actually failed. A good prediction is of course when many, if not all, the predicted slope will actually failed (or have actually failed for the case of back analysis). There are four Slope Assessment Systems (SAS) that have been developed by the Public Works Department (PWD) of Malaysia for predicting landslide at the micro level. They are the Slope Maintenance System (SMS), Slope Priority Ranking System (SPRS), Slope Information Management System (SIMS) and the Slope Management and Risk Tracking System (SMART). The two later systems, that are currently in used, i.e. the SIMS and the SMART, are evaluated and discussed in detail in this study.

The Slope Information Management System (SIMS) was developed in 2002 as a cooperation effort between the Public Works Department and the Japanese International Cooperation Agency [15]. The hazard score used was adopted from Japanese experience in Japan. Parameters considered include topography, geometry, material, geological structure, deformation, surface condition and countermeasure effectiveness.

The Slope Management and Risk Tracking Systems (SMART) is the latest slope management system developed by the PWD. The hazard score or instability score [IS] ranges from 0 to 1 and is derived through the integration of results from three assessment methods:statistical method (using stepwise discriminant function analysis and then converted into probability), deterministic method (the factor of safety determine by combined hydrology and stability model or CHASM and then converted to the probability using MonteCarlo Analysis) and if when appropriate, expert knowledge [16]. The system was developed based on the Tamparuli-Sandakan road in Sabah, Malaysia, where there have been numerous failures. This road is underlain largely by the meta-sediment formation.

Roads are the main type of transportation system in most countries of the world. In Malaysia, the total length of roads has been increased by more than three folds, from $21,914 \mathrm{~km}$ in 1980 to $78,433 \mathrm{~km}$ in 2003 [17]. About $30 \%$ of these roads traversed through or located on hilly and mountainous areas. Landslides occurrences along these hilly and mountainous roads have been reported from time to time, in both cut and natural slopes. Normally landslides occurred during the wet (rainy) season, from October to January every year. Study conducted in year 2000 along 6 selected hilly and mountainous roads shows that out of 444 various types of landslides, 420 occurred in cut and natural slopes [17].

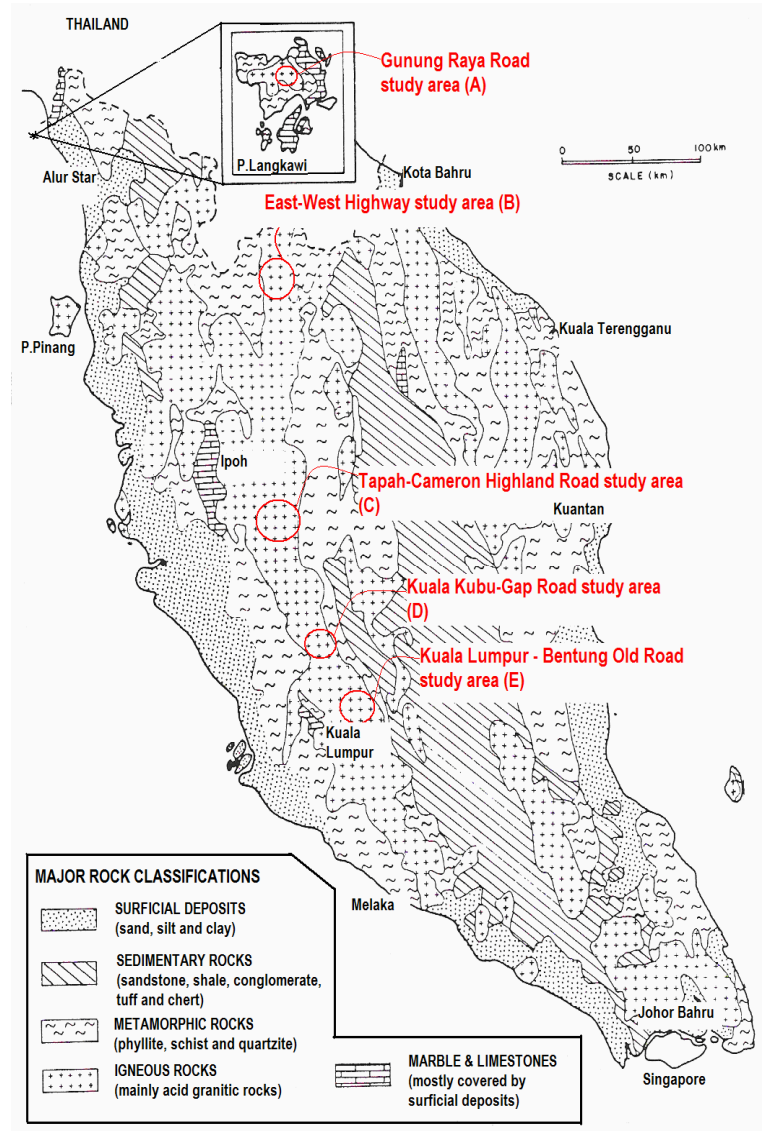

Fig. 1: Locations of Field Sites and General Geology of Peninsular Malaysia [9] 
Granite is the major rock that dominates virtually all the major mountain ranges with summits exceeding 2,000 meter in Malaysia [18]. More than $75 \%$ of the roads that traversed through the hilly and mountainous areas are cut through and/or underlain by the granitic formation. At least four major trunk roads and highway traversed through the Main Range granite formation of Peninsular Malaysia, namely the East-West highway (Gerik-Jeli), the Tapah-Cameron Highland road, the Kuala Kubu Baru-Gap road and the Kuala LumpurBentong Old road, as shown in Fig. 1. These four roads experienced numerous numbers of landslides occurrences in the past, which was caused disruption, injuries and losses to life and economy.

For evaluating the accuracy and reliability of the existing SAS in predicting landslides, slope assessment data along three different sites underlain by granitic formation, namely the Gunung Raya road in Langkawi Island, Malaysia (Site A) and the East-West highway (Gerik-Jeli, Site B) and the Kuala Kubu Baru-Gap road (Site D) of the Main Range granite, as shown in Fig. 1, were used. The slope inventory data such as slope height, slope angle, soil type, weathering grade, was collected/compiled over a ten-year period, from 1994 to 2004. These data were obtained from previous record as well as through site visit (walkthrough survey). Landslide occurrences were determined either from written history record, difference in aerial photo, or difference in sketches of the data collection performa and the current site condition. Data prior to the occurrence of the landslides were used as input for the SAS.

For the case of the Gunung Raya road (Site A), there are 15 numbers of past and 10 numbers of recent landslides that occurred after a period of heavy rainfall in September 2003. Generally the type of landslide that occurred along this road was shallow slides and severe sheet erosion. One big deep-seated landslide occurred at KM 5.9 that caused one fatality. Data from 10 of the landslides were used as input for the evaluation of the existing SAS. For the case of the East-West highway, 20 numbers of past and 12 numbers of recent landslides were reported between the periods of 1994 to 2001. Due to heavy rainfall in November 2003, more than 100 recent landslides occurred along the Kuala Kubu BaruGap road (Site D). Data from 21 of the recent landslides and 31 numbers of past landslide, mostly shallow slides, were used in this study as input for evaluating the existing SAS.

Evaluation of the Existing SAS: Thirty four (34) number of cut and natural slopes along the Gunung Raya road, 53 number of cut and natural slopes of the East-West Highway and 52 number of cut and natural slopes along the Kuala Kubu Baru-Gap Road was assessed using two slope assessment systems, namely the Slope Information Management System (SIMS) and Slope Management and Risk Tracking System
(SMART). The results obtained in term of number of slopes classified as high and very high hazard and numbers of slopes that actually fail are shown in Table 1.

Table 1: Summary of Comparative Study on Existing SAS in Predicting Landslide

\begin{tabular}{lcc}
\hline Prediction & SIMS & SMART \\
\hline $\begin{array}{l}\text { Number of slopes assessed } \\
\text { Numbers of recent landslide } \\
\text { or failed slope }\end{array}$ & 139 & 139 \\
$\begin{array}{l}\text { Numbers of slope classified } \\
\text { as High and Very }\end{array}$ & 44 & 44 \\
$\begin{array}{l}\text { High Hazard } \\
\text { Number of slopes classified }\end{array}$ & 2 & 72 \\
$\begin{array}{l}\text { as High and Very } \\
\text { High Hazard that actually failed }\end{array}$ & 1 & 27 \\
Percentage of (4) compared with (2) & $2 \%$ & $61 \%$ \\
\hline
\end{tabular}

From the table above, it can be seen that the SMART over-predict the number of slopes with high and very high hazard compared to the actual failure, while the SIM gives a gross under-prediction. In term prediction accuracy, which is defined as percentage of number of slopes classified as high and very high hazard that actually failed, the SMART gives $61 \%$ compared with SIMS of only $2 \%$.

For the case of the SIMS, it uses hazard score developed from other country. This appears to be its main defect. While for the case of the SMART, its current database derived only from the meta-sediment formations is apparently not sufficient to be extrapolated to the granitic formation considered in this study.

Development of the New SAS: Because of the apparent lack of accuracy of the existing SAS in predicting landslides, an attempt is made in this study to develop a new SAS. The same slope inventory data of failed and stable slopes (or without sign of failure) was analyzed using the stepwise discriminant analysis, similar to that used in the SMART. Statistical analysis is chosen because there are abundance of slopes inventory and landslides database collected for the past ten years that can be used. Furthermore, the statistical analysis can easily be conducted based on 'black-box' approaches to determine the significant slopes parameters and its coefficients that will be used in the linear model. The linear model produced by the statistical analysis can easily be applied and verified by others. This is good in term of objectivity compared to other methods such as heuristic method where it depends on experience of geomorphologists and where the results will vary and cannot be verified by other geomorphologists.

In the stepwise discriminant analysis, data on numerous slope parameters (such as slope angle, slope height, percentage of slope uncovered) prior to landslide or slope failure occurrences are complied/collected, 
American J. Environ. Sci., 1 (2): 90-96, 2005

Table 2: Sub-Parameters of Slope Feature Used in the Model Development

\begin{tabular}{|c|c|c|c|}
\hline Sub-Parameters & Ranges (Classes) & Sub-Parameters & Ranges (Classes) \\
\hline Slope feature & Near crest (1) & Main cover type & Trees (1) \\
\hline \multirow[t]{2}{*}{ location/position } & Mid-slope (2) & & Shrub (2) \\
\hline & Near toe (3) & & Grass (3) \\
\hline \multirow[t]{4}{*}{ Height of slope (m) } & $<10(1)$ & & Artificial cover (4) \\
\hline & 10 to $20(2)$ & $\%$ of Feature Uncovered & $<10(1)$ \\
\hline & 20 to $30(3)$ & & 10 to $30(2)$ \\
\hline & $>30(4)$ & & $>30(3)$ \\
\hline \multirow[t]{3}{*}{ Slope angle } & $<45(1)$ & Soil type & Sandy (1) \\
\hline & 45 to $63(2)$ & & Silty (2) \\
\hline & $>63(3)$ & & Clayey (3) \\
\hline Feature Aspect in & 0 to $90(1)$ & Presence of Rock & Yes (0) \\
\hline \multirow[t]{3}{*}{ Degrees } & 90 to $180(2)$ & Exposure & No (2) \\
\hline & 180 to $270(3)$ & $\%$ Rock Exposure & 0 to 25 (1) \\
\hline & 270 to $360(4)$ & & 26 to $50(2)$ \\
\hline \multirow[t]{3}{*}{ Plan profile } & Convex (1) & & 51 to $75(3)$ \\
\hline & Concave (2) & & 76 to $100(4)$ \\
\hline & Straight (3) & Weathering grade & I to II (1) \\
\hline \multirow[t]{3}{*}{ Cross profile shape } & Convex (1) & & III to IV (2) \\
\hline & Concave (2) & & $\mathrm{V}$ to VI (3) \\
\hline & Straight (3) & Rock Condition Profile & Grade III or less (1) \\
\hline \multirow[t]{4}{*}{ Feature Area $\left(\mathrm{m}^{2}\right)$} & $<2,500(1)$ & & Grade III and Grade IV (2) \\
\hline & 5,000 to $7,500(2)$ & & Grade IV to Grade VI (3) \\
\hline & 7,500 to $10,000(3)$ & & $\begin{array}{l}\text { Grade IV to Grade VI with } \\
\text { corestone boulders (4) }\end{array}$ \\
\hline & $>10,000(4)$ & & Colluvium (5) \\
\hline \multirow[t]{4}{*}{ Distance to Ridge (m) } & $<50(1)$ & Bench Drain & Yes $(0)$ \\
\hline & $50-149(2)$ & & No (2) \\
\hline & $150-249(3)$ & Horizontal drain & Yes $(0)$ \\
\hline & $>250(4)$ & & No (2) \\
\hline Batter / Bench & $<5(1)$ & Roadside drain/Toe & Yes (0) \\
\hline \multirow[t]{4}{*}{ Height (m) } & $5-9.9(2)$ & drain & No (2) \\
\hline & $10-14.9(3)$ & Number of water courses & $0(0)$ \\
\hline & $15-19.9(4)$ & within features & $1(1)$ \\
\hline & $>20(5)$ & & $2(2)$ \\
\hline \multirow[t]{4}{*}{ Slope shape } & Simple (1) & Erosion & No $(0)$ \\
\hline & Planar (2) & & Yes (2) \\
\hline & Asymmetrical (3) & & \\
\hline & Compound (4) & & \\
\hline
\end{tabular}

separated into failed and stable group and analyzed. Through the analysis, the significant parameter(s) in discriminating the failed and stable group and their regression coefficient as the best predictors of future landslide occurrences are determined. In this analysis, a model of discrimination is built step-by-step. Specifically, at each step all parameters are reviewed and evaluated to determine which one that will contribute most to the discrimination between the groups. That parameter will then be included in the model and the process starts again. The general regression model used for the computation of discriminant function $(Y)$ representing the instability score is as shown below;

$Y=d_{1} V_{1}+d_{2} V_{2}+\ldots+d_{n} V_{n}+C$

Where, $d_{l}, d_{2} \ldots d_{n}$ are discriminant coefficient, $V_{l}$, $V_{2}, \ldots V_{n}$ are significant variables / parameters and $C$ is a constant or model error.
One hundred and thirty nine (139) numbers of cut and natural slopes feature underlain by granitic formation from the three sites; the Gunung Raya road (Site A), the East-West highway (Site B) and the Kuala Kubu Baru-Gap road (Site D) were used in the development of the new SAS. The slopes features were then divided into two groups; 86 numbers of past and recent failed slopes and 53 numbers of stable slopes.

From the available data, 22 numbers of parameters or variables for every slope features that related to the landslide occurrence was selected in the development model as listed in Table 2. All slope data in form of continuous variables or parameters was transformed into various classes and it was used in the statistical analysis and regression equation for the computation of instability score (individual discriminant and regression function scores).

Twenty two numbers of slope parameters of failed and stable slopes were analyzed using the stepwise discriminant analysis in an attempt to determine 
parameters that can best discriminates the failed and stable slopes. The analysis was conducted using significant value of 0.15 to enter and 0.20 to remove the parameters in the analysis. The result of the analysis showed that there are nine significant parameters that can separate the failed and stable slopes, namely; slope angle, feature area, distance to ridge, slope shape, $\%$ of feature uncovered, presence of rock exposure, bench drain, horizontal drain and erosion. Discriminant function is then calculated using general regression formula (equation 1) and using canonical discriminant function coefficients as shown in Table 3.

Table 3: Canonical Discriminant Function Coefficients for the New SAS

\begin{tabular}{llc}
\hline Parameter/Variable & Label & Function \\
\hline Slope angle & Angle & 0.482 \\
Feature area & Feat-are & 0.601 \\
Distance to ridge & dst_ridg & 0.329 \\
Slope shape & slp_shp & -0.210 \\
\% of feature uncovered & uncover & 0.419 \\
Presence of rock exposure & rexp & 0.444 \\
Presence of bench drain & bench_d & 0.743 \\
Presence of horizontal drain & hori_d & 0.372 \\
Presence of erosion & erosion & 0.747 \\
Constant & & -6.328 \\
\hline
\end{tabular}

The nine-parameter equation produced from the analysis is as follows:

$$
\begin{aligned}
Y= & 0.482(\text { angle })+0.601(\text { feat-are })+0.329(\text { dst_ridg })- \\
& 0.210(\text { slp_shp })+0.419(\text { uncover })+0.444(\text { rexp })+ \\
& 0.743(\text { bench_d })+0.372(\text { hori_d })+0.747(\text { erosion })- \\
& 6.328
\end{aligned}
$$

Discriminant function of both the failed and stable slopes then can be computed using this equation (Eq. 2). The boundary of discriminant function separating these two groups (failed and stable) is calculated using average of this two groups mean, which can be determined statistically as shown in the histogram and normal curve plots in Fig. 2 and 3.

Groups mean for stable and failed slopes are -0.88 and 0.54 respectively. The value of discriminant function separating these two groups (noted as $g$ ) can be calculated using Eq. 3 as follow:

$g=\left(Y_{f}+Y_{s}\right) / 2$,

Where, $Y_{f}=$ Mean of failed group

$Y_{s}=$ Mean of stable group

Value of $g$ for the new SAS is:

$$
g=(0.54-0.88) / 2
$$$$
=-0.17
$$

Using this $g$ value, the boundary condition separating failed and stable slopes is as follow:
Stable if $Y<-0.17$, Otherwise failed.

The hazard rating is designed using the maximum and minimum value of discriminant function. The maximum value of discriminant function is 4.497 and minimum value is -5.337 . Table 4 below shows the designed hazard rating.

Table 4: Designed Hazard Rating

\begin{tabular}{ll}
\hline Range of $Y$ & Rating \\
\hline 2.164 to 4.497 & Very High \\
-0.17 to 2.164 & High \\
-2.584 to -0.17 & Low \\
-5.337 to -2.584 & Very Low \\
\hline
\end{tabular}

Table 5: Accuracy and Percentage of Correct Classification of New SAS in Predicting Landslides

\begin{tabular}{lc}
\hline & New SAS \\
\hline $\begin{array}{l}\text { Number of slopes assessed } \\
\text { Numbers of actual landslide or failed slope }\end{array}$ & 139 \\
Numbers of slope classified & 86 \\
as High and Very High Hazard & 74 \\
$\begin{array}{l}\text { Number of slopes classified as High } \\
\text { and Very High Hazard that actually failed }\end{array}$ & 66 \\
Percentage of (4) compared with (2) & $77 \%$ \\
\hline
\end{tabular}

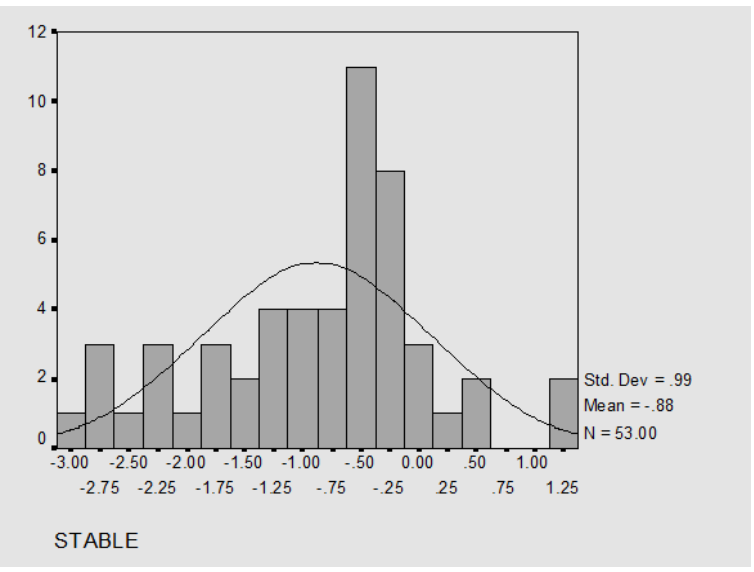

Fig. 2: Histogram Plot and Normal Curve of Stable Slope

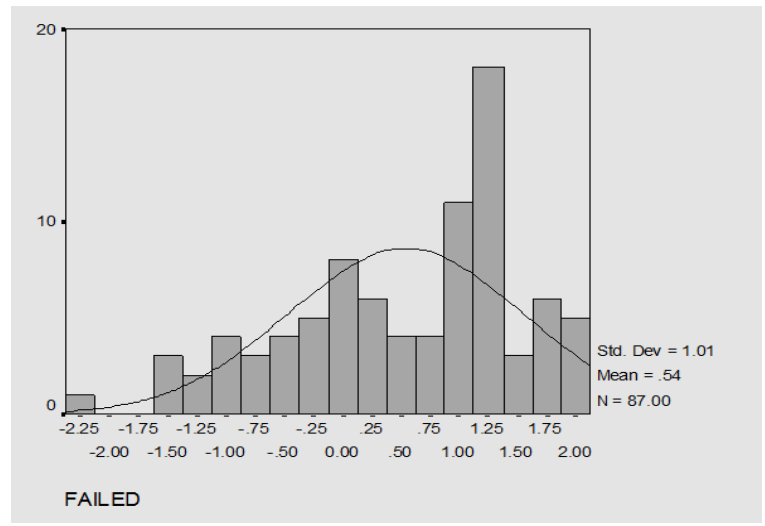

Fig. 3: Histogram Plot and Normal Curve of Failed Slope 
Table 6: Comparison of the Existing SAS with the New SAS for Predicting Landslides for 2 New Sites

\begin{tabular}{lccc}
\hline & New SAS & SIMS & SMART \\
\hline Number of slopes assessed & 36 & 36 & 36 \\
Numbers of recent landslide or failed slope & 25 & 25 & 25 \\
Numbers of slope classified as High and Very High Hazard & 28 & 0 & 8 \\
Number of slopes classified as High and very High Hazard that actually failed & 24 & 0 & 7 \\
Percentage of (4) compared with (2) & $96 \%$ & 0 & $28 \%$ \\
\hline
\end{tabular}

Table 5 shows a summary result of slope assessment using the new SAS on 139 numbers of slopes under study. As shown the number of slopes classified with high to very high hazard is reasonably close to the number of slopes that have actually failed. In term of prediction accuracy, the new model appears to be able to achieve an accuracy of $77 \%$, which is better than the existing SAS considered in this study.

Comparison of the Existing SAS with the New SAS: It is of interest to compare the performance of the two existing SAS with the new SAS is predicting landslide for sites other then the one used for the development of the new SAS to eliminate biasness in the statistics. For this purpose, two new sites underlain by granitic formation are considered. Data from 21 slopes along the Tapah-Cameron Highland road (Site C) and 15 slopes along the Kuala Lumpur-Bentung old road (Site E, Fig. 1) were used. Heavy rainfall caused a number of landslides along both roads. Some 13 recent landslides occurred along the Tapah-Cameron Highland road from 1994 to 2000. For the case of the Kuala Lumpur-Bentung old road, 12 recent landslides occurred a period of heavy rainfall in November 2003. The results of the comparative study are shown in Table 6.

As shown, the new SAS appears to show a good capability in predicting landslides in the granitic formation. The numbers of slopes classified with high to very hazard match closely those of the actual failure. Likewise the percentage of correct prediction is over $90 \%$. The accuracy of the existing SAS such as the SMART is only a low $28 \%$. This again reinforced the earlier argument that system developed for different rock formation could not be used. So is the case of the SIMS that utilized hazard score developed from another country.

\section{CONCLUSION}

From the results of this study, it appears that none of the existing SAS, i.e. the Slope Information Management System (SIMS) and the Slope Management and Risk Tracking System (SMART), is satisfactory for predicting landslide in granitic formation.
The reasons for the apparent poor predicting capability of the existing SAS are several. For the case of the SIMS, it uses hazard score developed from another country. While for the case of the SMART, it current database, which is derived from the meta-sediment formations, is apparently not suitable to be extrapolated for the granitic formation considered in this study.

A new SAS was developed using nine-parameters equation that is based on the stepwise discriminant analysis. The new SAS appears to show a much better capability in predicting landslides in granitic formations.

\section{REFERENCES}

1. Cruden, D.M., 1991. A simple definition of a landslide. Bull. Intl. Association of Eng. Geol., 43: 27-29.

2. Gerath, R., O. Hungr and D. van Dine, 1997. Terrain stability mapping in British Columbia. Resources Inventory Committee, Province of British Columbia. (http://srmwww.gov.bc.ca/risc/ pubs/earthsci/terrain2).

3. Abdullah, K., 1996. Design of a laboratory model for the study of the overall slope stability in the tropics. M. Sc. Thesis. Heriot-Watt University, Edinburgh.

4. Shuster, S.R.L., 1995. Reducing Landslide Risk in Urban Areas- Experience in the United States. In: Urban Disaster Mitigation- The Role of Engineering and Technology. Cheng and Sheu (Ed). Elsevier, pp: 217-230.

5. Dai, F.C., C.F. Lee and Y.Y. Ngai, 2002. Landslide risk assessment and management. An Overview. Eng. Geol., 64: 65-87.

6. Varnes, D.J., 1984. Landslide hazard zonation: A review of principles and practice. UNESCO, Natural Hazards, 3: 61.

7. Soeters, R. and C.J. van Westen, 1996. Slope instability, recognition, analysis and zonation. In Landslides: Investigation and Mitigation. Special Report 247. Transportation Research Board, National Research Council. National Academy Press. Washington, DC, pp: 129-177. 
8. Hussein, A.N., H. Omar and S. Jamaludin, 2004. Slope Assessment and Management. In Tropical Residual Soils Engineering, Huat, Gue and Ali (Eds). Balkema, London, pp: 103-120.

9. Irigaray, C. and J. Chacón, 1996. Comparative analysis of methods for landslide susceptibility mapping. Proc. $8^{\text {th }}$ Intl. Conf. and Field Trip on Landslides. Spain. Balkema, Rotterdam, pp: 373-383.

10. Ali, J.S.M., 2000. Risk Assessment of Landslide Using Fuzzy Theory. In Landslides in Research, Theory and Practice. London: Thomas Telford, pp: 31-36.

11. Rosenbaum, M.S., K. Senneset and M.E. Popescu, 1997. Assessing the Likelihood of Landsliderelated Hazards on a Regional Scale. In Engineering Geology and the Environment. Marinos, Koukis, Tsiambaos and Stournaras (Eds). Balkema, Rotterdam, pp: 1009-1014.

12. Tangestani, M.H., 2003. Landslide susceptibility mapping using the fuzzy gamma operation in a GIS, Kakan catchment area, Iran. Proc. Map of India Conf. GISdevelopment.net., pp: 7.

13. Kubota, T., 1996. Study on the fractal dimensions and geological condition of landslides. Proc. $8^{\text {th }}$ Intl. Conf. Field Trip on Landslides. Spain. Balkema, Rotterdam, pp: 385-392.
14. Yi, S., R. Li, X. Pu and S. Fu, 2000. The Fractal Characteristics of the Temporal and Spatial Distribution of the Zameila Mountain Landslide Activities and its Fracture Structure inn Tibet, China. In Landslides in Research, Theory and Practice. London: Thomas Telford, pp: 1605-1608.

15. JICA and PWD, 2002. The study on slope disaster management for federal roads in Malaysia. Public Works Department, Malaysia. Final Report. Vol. 1.

16. PWD Malaysia, 2004. Slope protection study for Federal Route 22, Tamparuli-Sandakan, Sabah. Draft Final Report. Public Works Department, Malaysia.

17. PWD Malaysia, 2004. Statistik Jalan 2004. Public Works Department, Malaysia.

18. Mun, K.P., 1985. Sampling and testing of residual soils in Malaysia. J. Southeast Asian Geotechnical Society, pp: 109-120.

19. Komoo, I. and S.N. Mogana, 1988. Physical characterization of weathering profile of clastic metasediments in Peninsular Malaysia. Proc. Geomechanics in Tropical Soils. Singapore, 1: $37-42$. 